\title{
Joanna Poyago-Theotoky and Alessandro Tampieri* University Competition and Transnational Education: The Choice of Branch Campus
}

DOI 10.1515/bejte-2015-0052

Published online May 27, 2016

Abstract: We present a theoretical framework in which an elitist and a non-elitist university in a developed country compete by choosing admission standards and deciding whether or not to open a branch campus in a developing country. Students from a developing country attend university if either a branch campus is opened or, they can afford to move to the developed country. We find that the elitist university is more likely to open a branch campus. This result is reversed if the gain, in terms of prestige, to attend the home campus of the elitist university more than offsets a student's mobility costs. A rise in the graduate wage increases the incentive for opening a branch campus, although this incentive is stronger for the elitist university.

Keywords: university competition, branch campus, admission standards, transnational education

JEL Classification: I23, L13, F23

\section{Introduction}

A rapidly growing number of universities across the world are engaging in transnational education activities by establishing branch campuses in other countries. Transnational education is defined as arrangements in which courses or degree programmes offered by an institution in one country are delivered to students located in a different country (Ziguras 2003).

The evidence shows that the international branch campus market has become more competitive. Higher education institutions from 22 countries have established branch campuses abroad compared with 17 countries in 2006. Most of these campuses (111 out of 162) were established by institutions

\footnotetext{
*Corresponding author: Alessandro Tampieri, Faculty of Law, Economics and Finance, University of Luxembourg, Avenue de la Faencerie 162a, L - 1511 Luxembourg, E-mail: tamp79@gmail.com Joanna Poyago-Theotoky, School of Economics, La Trobe University, Melbourne, Victoria 3086, Australia; GEOLAB, Ionian University, Corfu, Greece; Rimini Centre for Economic Research (RCEA), Rimini, Italy, E-mail: j.poyago-theotoky@latrobe.edu.au
} 
in the Anglophone nations, the US continuing to overshadow all others with its 78 offshore bases accounting for $48 \%$ of the total. The US is followed by Australia with 14 campuses, $9 \%$ of the total number, the UK with 13 or $8 \%$ of the total, and France and India each with 11. Several other countries, including Mexico with seven small campuses, the Netherlands with five, Malaysia with four and Canada and Ireland with three each, operate multiple branches abroad. Since 2006, institutions from five new source countries have established at least one overseas campus: these are Lebanon, Malaysia, South Korea, Sri Lanka and Switzerland (Becker 2009).

In the higher education economics literature, contributions on the effects of branch campuses are scarce, with few but notable exceptions. Lien (2006) analyses a university market in a developing country, with a domestic university and the branch campus of a foreign university. The domestic university provides education in both global knowledge (commonly accepted and being helpful for developing countries probably in the future) and local knowledge (being directly helpful for developing countries), whereas the branch campus specializes in global knowledge education only. Students have different learning ability in global knowledge (but not in local knowledge) and they choose which university to attend based upon the expected wages. If graduates from the branch campus have opportunities to work abroad and earn higher incomes, then an increase in the wage in the foreign country will lead to a reduction in local knowledge production. Lien (2008) extends Lien (2006) by considering different qualities of the branch campus. Finally, Lien and Wang (2010) examine student decisions in a developing country about whether to attend the local university or study abroad. All these papers focus on the effects of a branch campus on the question of brain drain on the developing country and treat the decision to open a branch campus as exogenous and not determined in equilibrium. Further, there is no university competition, in the sense that universities do not act strategically.

The growing importance of transnational education activities, such as the establishment of branch campuses, and its role in competition among universities appears not to have been investigated thoroughly in the literature. This is the main objective of the present paper. The paper is also related to the literature on spatial competition among universities (Del Rey 2001; De Fraja and Iossa 2002; Cesri and Paolini 2013; Carroni, Cesi and Paolini 2015). In particular, the

1 In De Fraja and Iossa (2002), the two universities are located in different towns in a single country and compete by setting admission standards only. They show that universities choose the same admission standard only when the mobility cost (i. e. the cost for a student to attend 
modelling framework borrows some elements from the analysis of university competition of De Fraja and Iossa (2002). ${ }^{1}$

To the best of our knowledge, this is the first paper to analyse the decision of investing in a branch campus within a competitive environment. In a simple stylised model, two universities operating in a developed country compete by choosing their admission standards and deciding whether or not to open a branch campus in a developing country. We show that one of the two universities is "elitist", in the sense that it sets its admission standard higher than its competitor. A student who is admitted to university will graduate with certainty and will obtain a higher income in the job market. Students from a developing country can attend university if a branch campus is opened or if they are "privileged", i. e. they can borrow money (from the family or the financial sector) to move to the developed country. So students decisions' depend on travel costs and their borrowing constraints while university decisions depend on the fixed investment costs of opening the branch campus and their revenues.

We investigate the relationship between investment costs and graduate wages. Very high investment costs discourage the opening of a branch campus. An increase in the graduate wage increases the incentive for opening a branch campus, although the incentive is stronger for the elitist than the non-elitist university. This is due to the fact that students prefer to attend the elitist university, so that the demand for higher education is filled from the elitist university and the nonelitist university covers the remainder. Therefore three possible equilibria emerge: (i) no branch campus is established, (ii) one branch campus is opened by the elitist university only and (iii) each university opens a branch campus. Surprisingly, an increase in the proportion of privileged students increases the chance of an equilibrium of type (ii) to the detriment of equilibrium (i). Indeed, the presence of more privileged students entails that opening a branch campus is less profitable (in the limit case where all students are privileged, there is no incentive at all since all students are able to move to the main campus), so one would expect that the university who gains the most from opening a branch campus will do it with lower probability. The intuition is the following: an increase in privileged students reduces the demand for university from students who stay in the developing country. The non-elitist university suffers from the fall in the demand relatively

university away from her town) is high; when the mobility cost is very low, there is no pure strategy equilibrium, whereas asymmetric equilibria exist for intermediate values of the mobility cost. Compared to De Fraja and Iossa (2002), in the present paper universities are located in the same country, and have the option of opening a branch campus overseas by bearing an additional cost. We show that that one university always sets its standard higher than the competitor. In other words, we focus on asymmetric cases. 
more than the elitist university, given the higher benefit from the latter from opening a branch campus.

We also examine the case where a "top university" competes with a non-elitist university. The top university sets a higher admission standard than the non-elitist university. In addition, the gain in terms of prestige and reputation in attending the home campus of a top university more than offsets mobility costs - this is the defining characteristic for a top university in this context. This of course affects the demand for attending the home campus of the top university, which remains high even if a branch campus is opened. In other words, if a student from a developing country can afford it, she will attend the home campus of a top university irrespective of the university choice of branch campus. The strict preference towards the home campus of top universities is in line with empirical evidence showing a large number of international students attending prestigious American and British Universities, even when these insitutions open a branch campus. In this case, the results strictly depend on the proportion of privileged students. For a low proportion, the results are qualitatively similar to the baseline case. However, when the proportion of privileged students is high, the market configuration in equilibrium exhibits the opening of a branch campus by the non-elitist university only.

The remainder of the paper is organised as follows. Section 2 presents the modelling framework and provides the equilibrium analysis for the baseline case (Sections 2.1-2.5). Section 2.6 considers a market with a top university and a non-elitist university. Section 3 provides some brief concluding remarks.

\section{The Model}

Consider a large population of potential students that is evenly distributed in two countries, 1 and 2. In each country the number of students is normalised to one. Country 1 can be thought of as a "developed" country. In Country 1 two universities, denoted by $A$ and $B$, are established. Country 2 can be thought as a "developing" country, and we assume that there are no local universities. ${ }^{2}$ However, university

2 This is a simplifying assumption in order to make the analysis more compact and tractable. The focus of the paper is on the choice of opening up a branch campus by the foreign universities. In the present work, local universities do not engage in transnational activities in a reciprocal manner. 
$A$ and $B$ may decide to open a branch campus (from now on, BC) in Country 2. The timing of the interaction between students and universities is modelled as a two-stage game where in stage 1 universities decide whether to open a branch campus and in stage 2 universities set admission standards while students choose which university/campus to enrol in. ${ }^{3}$

\subsection{Universities}

Following De Fraja and Iossa (2002), the objective function of a university, $i$, $i=A, B$, is written as:

$$
W\left(n_{i}, R_{i}, \Theta_{i}\right)-\Phi_{i},
$$

where $W$ captures the three elements that a university bureaucracy ${ }^{4}$ cares about: - the number of enrolling students $n_{i}$, where

$$
n_{i}= \begin{cases}n_{i 1}+n_{i 2} & \text { if a BC is opened } \\ n_{i 1} & \text { if no BC is opened }\end{cases}
$$

- $\quad$ the quality of the student body $\Theta_{i}$ (i. e. average ability of students attending $i$ ), and

- $\quad$ the expenditure on research $R_{i}$,

while

$$
\Phi_{i}= \begin{cases}F & \text { if a BC is opened } \\ 0 & \text { if no BC is opened }\end{cases}
$$

are the fixed costs associated with opening a branch campus. The first partial derivatives of $W$ in eq. [1] are all positive, and $W_{n n}(\cdot), W_{R R}(\cdot), W_{\Theta \Theta}(\cdot)<0$, and that the second cross derivatives are sufficiently small so that the relevant secondorder conditions are satisfied. This implies that $W$ is approximately separable.

Each university has a budget determined by the amount of tuition fees collected from the enrolled students, $f n_{i}$, where $f>0$ represents the fees per

3 See Section 2.3 for more details.

4 We assume that a university is run by a bureaucracy.

5 This simplifying assumption can be justified as a reasonable approximation of current practice in many European countries and beyond but also because it allows us to analyse the decisions on transnational investment in isolation from decisions about raising revenues. See Pepall and Richards (2014) for an analysis of fee setting in a different context. 
student. Tuition fees $f$ are set exogenously: universities are not free to choose what students are charged in fees. ${ }^{5}$ Therefore, each university:

- decides whether or not to open a BC in Country 2 at a fixed cost $F>0$; and

- chooses the required standard necessary to admit a student in each location/campus. We denote this by $x_{i j} \in\left[\underline{x}_{i j}, 1\right], i=A, B, j=1,2$, where $\underline{x}_{i j}>0$ is the lowest possible admission standard. This implies that only students who reach at least standard $x_{i j}$ are accepted at institution $i$ with campus in Country $j$.

Further, suppose that teaching $n_{i}$ students carries a cost of

$$
C\left(n_{i}\right)=\left\{\begin{array}{ll}
c\left(n_{1}\right)+c\left(n_{2}\right) & \text { if a BC is opened } \\
c\left(n_{1}\right) & \text { if no BC is opened }
\end{array},\right.
$$

with $c^{\prime}\left(n_{j}\right)>0, c^{\prime \prime}\left(n_{j}\right) \geq 0, j \in\{1,2\}$ and $\lim _{n \rightarrow 1} c^{\prime}\left(n_{j}\right)=+\infty$. Thus the teaching cost is considered separately for each university site. This assumption represents better a university technology in the real world: the costs are increasing and convex within each campus, due to the number of staff, classroom size, equipment, laboratories, and so on.

\subsection{Students}

Students differ in ability, denoted by $\theta \in[0,1]$. In each country, students' distribution by ability is $G(\theta)$, with $G(0)=0, G(1)=1$ and density $g(\theta)=G^{\prime}(\theta)$. The admission standard set by a university, $x_{i j}$, is in the same support as ability, so that $x_{i j} \in[0,1]$ and $x_{i j}=\theta_{i j}$ where $\theta_{i j}$ is the lowest ability student that can be accepted by university $i$ in Country $j .{ }^{6}$ If a student attends university, she graduates with certainty at the end of the university period. Still with certainty, in the labour market she will receive a wage surplus for being a graduate ("graduate wage") $S\left(x_{i j}\right)$, depending on the university admission threshold $x_{i j}$. Effectively the wage surplus captures the peer effects at university: the higher the admission standard, the smarter the people a student interacts with Del Rey

\footnotetext{
6 The results do not change by assuming that admission standards may change according to a student's origin. In equilibrium, universities would set the same standards to students coming from different countries. Our results may be interpreted as follows. Usually, a university admits foreign students by asking further requirements than a local student. An example can be a standardized test, or a language test. However, the extra requirement compensates for the lack of information about the education system of the student's country of origin.
} 
(2001), De Fraja and Iossa (2002) and Cesi and Paolini (2014). To put it simply, being with smart people makes you smarter.

A student's payoff function (if attending university) depends on her ability $\theta$, the admission standard, $x_{i j}$, the tuition fee, $f$ and the mobility cost $T$ :

$$
S\left(x_{i j}\right)+\theta-f-T,
$$

where $U\left(x_{i j}, \theta\right)=S\left(x_{i j}\right)+\theta$ is a student's utility with $S^{\prime}\left(x_{i j}\right)>0$, and

$$
T= \begin{cases}t & \text { if a student moves to attend university } \\ 0 & \text { if a student does not move. }\end{cases}
$$

For the sake of simplicity, we assume $S\left(\underline{x}_{i j}\right)>f$. In other words, the lowest possible graduate wage is higher than tuition fees. This ensures that every student is willing to attend university irrespective of $f$. A possible interpretation is that a government agency designs tuition fees in order to give incentives to the largest number of students to attend university. This assumption simplifies the analysis as $f$ does not play any role in determining the demand function of students, but only determines a university's budget.

To simplify the analysis, all students from Country 1 attend university in Country 1 , even if at least one BC is present in Country $2 .^{7}$ On the other hand, in Country 2 there is an exogenous number of students $\beta \in(0,1)$, denoted as "privileged" who can borrow, either from their family or the banking system, the amount of money to cover the mobility costs $t$. $\beta$ is independent of a student's level of ability.

A student who does not attend university has a reservation utility of $U(0,0)<U\left(x_{i j}, \theta\right)$, for all $x_{i j} \in\left[\underline{x}_{i j}, 1\right]$, so that a student from the developed country would surely attend university if admitted. A student from the developing country would surely attend university if admitted and either

- there is a $\mathrm{BC}$, or

- there is no BC but she belongs to the group of privileged students and $U\left(x_{i j}, \theta\right)-f \geq t$.

The next definition is convenient.

Definition 1: Let $t^{\star}$ denote the cost of moving to Country 1 such that

$$
U\left(x_{A 1}, \theta\right)-t^{\star}=U\left(x_{B 2}, \theta\right) .
$$

7 This is because we focus purely on the decision of a university's transnational investment in a $\mathrm{BC}$. 


\subsection{Students' Admission and University Attendance}

In this section we establish university attendance which depends on the admission standard/threshold set by each university. Using [1] we rewrite the payoff functions of the two universities as

$$
\pi_{i}\left(x_{A j}, x_{B j}\right)=W\left(n_{i}\left(x_{A j}, x_{B j}\right), f n_{i}\left(x_{A j}, x_{B j}\right)-c\left(n_{i}\left(x_{A j}, x_{B j}\right)\right), \Theta_{i}\left(x_{A j}, x_{B j}\right)\right)-\Phi_{i},
$$

where $n_{i}\left(x_{A j}, x_{B j}\right)$ and $\Theta_{i}\left(x_{A j}, x_{B j}\right)$ are the number of students admitted and the average quality of students at university $i, i=A, B$, respectively, given the admission standards $\left(x_{A j}, x_{B j}\right)$ for locations $j=1,2$. Notice that we have replaced research expenditure $R_{i}$ with $R_{i}=f n_{i}\left(x_{A j}, x_{B j}\right)-c\left(n_{i}\left(x_{A j}, x_{B j}\right)\right)$, i. e. the difference between total revenue from tuition fees and teaching costs.

It is clear that $\partial \Theta_{i} / \partial x_{i j}>0:$ an increase in a university's admission standard increases the average ability of that university's students. According to the timing of the game, universities set their admission standards following their decision on the opening (or not) of a branch campus. Therefore there are four distinct possibilities, depending on the first-stage subgames:

1. Neither university opens a branch campus, hence the relevant standards to set are $x_{A 1}$ and $x_{B 1}$.

2. University $A$ opens a branch campus; the standards to be set are $x_{A 1}, x_{A 2}$ and $x_{B 1}$.

3. University $B$ opens a branch campus; the standards to be set are $x_{A 1}, x_{B 1}$ and $x_{B 2}$.

4. Both universities open a branch campus; the relevant standards are $x_{A 1}, x_{A 2}$, $x_{B 1}$ and $x_{B 2}$.

A natural question arising here is whether the standards chosen will be symmetric, meaning that the universities set the same admission standards, or asymmetric, where universities choose different admission standards. A preliminary result is the following.

Lemma 1: Symmetric standards cannot be part of an equilibrium with positive student demand.

Proof: See Appendix A.1.

Lemma 1 establishes that an equilibrium requires setting different admission standards. 
In relation to subgame 4 (see above) we clarify that one can distinguish the following possibilities: (a) University $A$ sets a higher standard in both countries, (b) University $B$ sets a higher standard in both countries, (c) University $A$ sets a higher standard in country 1, (d) University $A$ sets a higher standard in Country 2. Cases (a) and (b) and cases (c) and (d) are clearly specular. In what follows, we focus on equilibria where university $A$ sets the higher standard in every country in which it operates, and we call university $A$ "elitist". 8 We therefore state,

Assumption 1: $x_{A j}>x_{B j}$.

The following propositions describe university attendance of students from Country 1 and 2, respectively.

Proposition 1: Consider students living in Country 1. Let university $i \in\{A, B\}$ set standard $x_{i 1}$, and Assumption 1 hold. A student attends university $A$ if $\theta \in\left[x_{A 1}, 1\right]$ and university $B$ if $\theta \in\left[x_{B 1}, x_{A 1}\right)$.

Proof: See the Appendix A.2.

The next proposition establishes university attendance of students from Country 2. For these students, university attendance depends on (i) whether or not one or two branch campuses are opened, and (ii), in the case where only university $B$ opens a branch campus, whether $t$ is greater or not than $t^{\star}$ (see Definition 1). Indeed, a student with high ability may be admitted to university $A$, but the mobility costs are high so that the student may prefer to attend the branch campus of university $B$. The equivalent of Proposition 1 for students of Country 2 follows.

Proposition 2: Consider students living in Country 2. Let university $i \in\{A, B\}$ set standard $x_{i j}$ in their site in Country $j$ with $x_{A j}>x_{B j}$ (assumption 1).

(i) No BC: a student attends university if she is privileged: in particular, university $A$ if $\theta \in\left[x_{A 1}, 1\right]$ and university $B$ if $\theta \in\left[x_{B 1}, x_{A 1}\right)$.

(ii) University $A$ operates BC: a student attends university $A$ if $\theta \in\left[x_{A 2}, 1\right]$ and university $B$ if privileged and $\theta \in\left[x_{B 1}, x_{A 1}\right)$.

(iii) Universities $A$ and $B$ operate BC: a student attends university $A$ if $\theta \in\left[x_{A 2}, 1\right]$ and university $B$ if $\theta \in\left[x_{B 2}, x_{A 2}\right)$.

8 It is plausible (and empirically observed) to expect that a university has higher prestige irrespective of the country in which it operates. 
(iv) University $B$ operates $\mathbf{B C}$, and $t \leq t^{\star}$ : a student attends university $A$ if privileged and $\theta \in\left[x_{A 1}, 1\right]$ and university $B$ either if non-privileged and $\theta \in\left[x_{A 1}, 1\right]$ or, if not privileged and $\theta \in\left[x_{B 2}, x_{A 1}\right)$.

(v) University $B$ operates $\mathrm{BC}$, and $t>t^{\star}$ : a student never attends university $A$, and attends university $B$ if $\theta \in\left[x_{B 2}, 1\right]$.

Propositions 1 and 2 allow us to simplify the interaction between universities and students so that, in the first stage, the strategy space is binary, and consists of the decision of whether to open (or not) a branch campus in country 2 and in the second stage, the strategy space is given by the admission standards, $x_{A j}, x_{B j} \in[0,1]$. The equilibrium concept is subgame perfect equilibrium by backward induction. Figure 1 depicts the timing of the game.

\section{\begin{tabular}{l|l} 
Stage $\mathbf{1}$ & Stage 2 \\
Universities decide whether to open a BC & $\rightarrow$ \\
Universities set their admission standard
\end{tabular}}

Figure 1: The simplified game.

To make further progress and obtain explicit closed-form solutions for the remainder of the paper we specify the functional relationships as follows:

$$
\begin{gathered}
U\left(x_{i j}, \theta\right)=w x_{i j}+\theta, \\
W\left(n_{i}, R_{i}, \Theta_{i}\right)=\sum_{j} n_{i j}\left(w x_{i j}+f-c n_{i j}\right), \\
c\left(n_{i j}\right)=c \sum_{j} n_{i j}^{2}, \\
G(\theta)=\theta,
\end{gathered}
$$

where $S\left(x_{i j}\right)=w x_{i j}, w>0$ is a graduate's wage. The specifications chosen (eqs [3], [4], [5] and [6]) respect the properties of the associated general functions. In particular, note that the average ability of students increases with $x_{i j}$. Finally, assuming a uniform distribution for ability is standard in the literature of university competition (Del Rey, 2001; De Fraja and Iossa, 2002; Cesi and Paolini, 2013 and Carroni, Cesi and Paolini 2015).

\subsection{Admission Standards}

The following Lemma 2 shows the number of admitted students and is a direct consequence of Propositions 1 and 2. 
Lemma 2: Let Assumption 1 hold. Then the number of students being admitted to each university is:

$$
\begin{aligned}
& n_{A}= \begin{cases}(1+\beta)\left(1-x_{A 1}\right) & \text { no } B C \\
\left(1-x_{A 1}\right)+\left(1-x_{A 2}\right) & \text { A BC } \\
(1+\beta)\left(1-x_{A 1}\right) & \text { B BC, A no BC for } t \leq t^{\star}, \\
\left(1-x_{A 1}\right) & B B C, \text { A no } B C \text { for } t>t^{\star} \\
\left(1-x_{A 1}\right)+\left(1-x_{A 2}\right) & B, A, B C\end{cases} \\
& n_{B}= \begin{cases}(1+\beta)\left(x_{A 1}-x_{B 1}\right) & \text { no } B C \\
\left(x_{A 1}-x_{B 1}\right)+\beta\left(x_{A 12}-x_{B 1}\right) & A B C \\
\sum_{j}^{1,2}\left(x_{A j}-x_{B j}\right) & A \text { and } B, B C \\
(1+\beta)\left(x_{A 1}-x_{B 1}\right)+(1-\beta)\left(1-x_{B 2}\right) & B B C, A \text { no } B C \text { and } t \leq t^{*} \\
\left(x_{A 1}-x_{B 1}\right)+\left(1-x_{B 2}\right) & B B C, \text { A no } B C \text { and } t>t^{*}\end{cases}
\end{aligned}
$$

Thus a university's problem in the second stage is given by

$$
\max _{x_{i j}} \sum_{j} n_{i j}\left(w x_{i j}+f-c n_{i j}\right)-\Phi_{i}
$$

where $j=1$ if a university does not open a $\mathrm{BC}$ and $j=1,2$, if a $\mathrm{BC}$ is opened. Thus the admission standard in equilibrium is denoted by $x_{i j}^{\star}=\arg \max \pi_{i}\left(x_{i j}\right)$. The four possible solutions (according to which university opens the BC) are $\left(x_{A}^{N N} ; x_{B}^{N N}\right)$, $\left(x_{A}^{F N} ; x_{B}^{F N}\right),\left(x_{A}^{N F} ; x_{B}^{N F}\right)$ and $\left(x_{A}^{N N} ; x_{B}^{N N}\right)$ is given by eqs [12], [14], [18] and [16], respectively, in Appendix A.1. Superscript $N N$ indicates that none of the universities opens a BC, superscript $F N$ denotes that university $A$ opens a BC and university $B$ does not. Conversely, superscript $N F$ says that university $A$ does not open a BC but university $B$ does. Finally, superscript $F F$ indicates that both universities open a BC.

Based on these results for the case where University B opens a BC and University A does not, Lemma 3 below provides the critical value for mobility cost $t^{\star}$ that determines whether a student from country 2 will attend country 1 or not (see Definition 1).

Lemma 3: Suppose that University $B$ opens a $B C$ while University $A$ does not. Then, a student from Country 2 with ability at least $\theta_{A}=x_{A}$ would either attend university $A$ in Country 1 for all $t \leq t^{\star}$, or attend the $B C$ of university $B$ for all $t>t^{\star}$, where 


$$
t^{\star} \equiv \frac{w c \beta(w+f)}{2(w+c)[w+c(1+\beta)]} .
$$

Proof: See Appendix A.4.

Notice that university $A(B)$ prefers $w x_{A}-t \leq(>) w x_{B}$, as shown by:

$$
\pi_{A 1}^{N F}-\pi_{A 2}^{N F}=\frac{\beta w(w+f)}{4(w+c)[w+c(1+\beta)]}>0,
$$

and

$$
\pi_{B 1}^{N F}-\pi_{B 2}^{N F}=-\frac{\beta w^{2}(w+f)\left[w^{2}(4-\beta)+2 w c(5+\beta)+c^{2}(6+4 \beta)\right]}{16(w+c)^{2}(w+2 c)}<0 .
$$

\subsection{Investment in $B C$}

In the first stage, each university decides whether to open a $\mathrm{BC}$ according to the competitor's strategy. For brevity, we focus on the case where $t \leq t^{\star}{ }^{9}$. The following table shows the payoff matrix according to whether university $A$ and $B$ decide to invest in a BC.

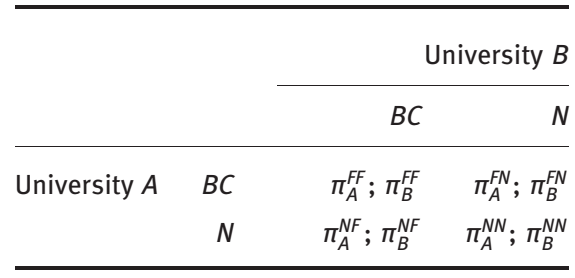

The full derivation of $\left(\pi_{A}^{N N} ; \pi_{B}^{N N}\right),\left(\pi_{A}^{F N} ; \pi_{B}^{F N}\right),\left(\pi_{A}^{N F} ; \pi_{B}^{N F}\right)$ and $\left(\pi_{A}^{N N} ; \pi_{B}^{N N}\right)$ is given by eqs [13], [15], [19] and [17], respectively, in Appendix A.1. This allows us to compare profits in every scenario and to find the equilibria in the decision of opening a BC. The subgame perfect equilibrium is therefore determined as the Nash equilibrium of the $2 \times 2$ payoff matrix above, according to values of the establishment (fixed) costs of opening a BC, $F$.

9 The computations for $t>t^{\star}$ are cumbersome, but bring about qualitatively similar results. Upon request, these results can be provided. 
Begin by examining the strategy of university $A$ according to university $B$ decisions. If university $B$ plays $B C$, university $A$ would do the same for $\pi_{A 1}^{F F}>\pi_{A 1}^{N F}$, whereas if university $B$ plays $N$, university $A$ would play $B C$ for $\pi_{A 1}^{F N}>\pi_{A 1}^{N N}$. Both these inequalities hold for all:

$$
F<F_{A} \equiv \frac{(w+f)^{2}[w(1-\beta)+c(1+\beta)]}{4(w+c)[w+c(1+\beta)]},
$$

so that $A$ has a dominant strategy: for $F<F_{A}$ it plays $B C$ and for $F>F_{A}$ it plays $N$. Invoking dominance, we now turn to the behaviour of university $B$. For $F<F_{A}$ university $A$ plays $B C$ so that university $B$ would also play $B C$ when $\pi_{B 1}^{F F}>\pi_{B 1}^{F N}$, which occurs for all:

$$
F<\widehat{F}_{B} \equiv \frac{(w+f)^{2}(w+2 c)^{2}[w(1-\beta)+c(1+\beta)]}{16(w+c)^{3}[w+c(1+\beta)]},
$$

and would play $N$ if $F>\widehat{F}_{B}$. For $F>F_{A}$ university $A$ plays $N$ so that university $B$ would play $B C$ for $\pi_{B 1}^{N F}>\pi_{B 1}^{N N}$, which occurs for:

$$
\begin{gathered}
F<\bar{F}_{B} \equiv \frac{w^{3}(4-\beta)(1-\beta)+c w^{2}\left(12-\beta^{2}(11-\beta)\right)(w+f)^{2}}{16(w+c)[w+c(1+\beta)]^{3}} \\
+\frac{4 w c^{2}(3-2 \beta)^{2}(1+\beta)^{2}+4 c^{3}(1+\beta)^{3}(w+f)^{2}}{16(w+c)[w+c(1+\beta)]^{3}}
\end{gathered}
$$

and would play $N$ for $F>\bar{F}_{B}$.

Notice that the chain of inequalities for the threshold levels is $F_{A}>\bar{F}_{B}>\widehat{F}_{B}$. Therefore, in conjunction with the preceding discussion, we establish the following proposition, which is one of the main results of this paper. ${ }^{10}$

Proposition 3: Let $w x_{i j}>t$ for all $i \in\{A, B\}, j \in\{1,2\}$ and $t \leq t^{\star}$. For all:

1. $F>F_{A}$, neither university opens a $B C$, the equilibrium is [N;N] (type 1);

2. $F_{A}>F>\widehat{F}_{B}$, university $A$ opens $a B C$ and university $B$ does not, the equilibrium is [BC;N] (type 2);

3. $F<\widehat{F}_{B}$, both universities open a $B C$, the equilibrium is [BC;BC] (type 3).

Figure 2 illustrates these equilibria for combination between the investment cost $F$ and the graduate wage $w$, for given $\beta$ and $c$. Also, notice that

$$
\left.F_{A}\right|_{w=0}=\left.\widehat{F}_{B}\right|_{w=0}=\frac{f^{2}}{4 C}
$$

10 It is easy to verify that the threshold $\bar{F}_{B}$ is irrelevant for the Nash equilibrium. 


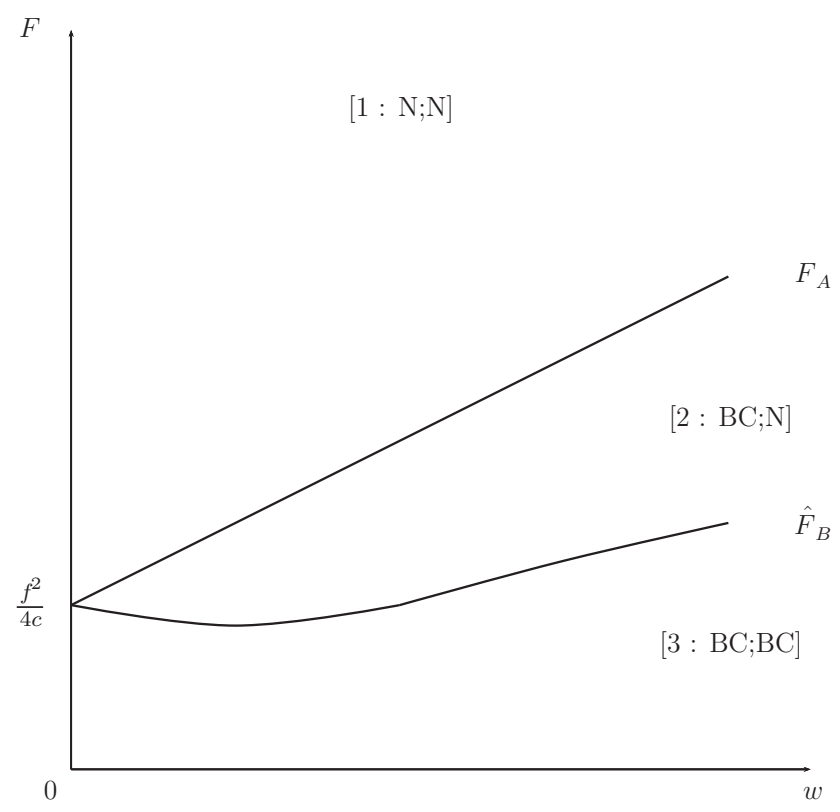

Figure 2: Illustration of proposition 3.

university $A$ gains more from the students' qualification $x$ than university $B$. Hence, the number of students $n$ has relatively more importance in determining $B$ 's profits. Students prefer to attend university $A$, so that the demand for higher education is filled from that institution, whereas university $B$ serves only the remainder of the demand for higher education. Therefore university $A$ has more incentives in investing in $B C$, given the same cost $F$.

Consider next how a variation in the share of privileged students may affect the equilibrium. Differentiating $\left(F_{A}-\widehat{F}_{B}\right)$ with respect to $\beta$ yields:

$$
\frac{\partial}{\partial \beta}\left(F_{A}-\widehat{F}_{B}\right)=\frac{w^{2}(w+f)^{2}(3 w+4 c)}{16(w+c)^{2}[w+c(1+\beta)]}>0 .
$$

Corollary 1: An increase in the number of privileged students increases the probability that university $A$ opens a $B C$ while university $B$ does not (equilibrium [2]).

The result described in Corollary 1 can be explained as follows. A raise in the number of privileged students reduces the demand for university from students in the developing country. The non-elitist university is more affected by the fall in the demand relatively more than the elitist university, given the higher benefit from the latter from opening a branch campus. 


\section{6 "Top" University}

The analysis carried out so far aimed at stressing the importance of mobility costs in university interaction. This approach is relevant in many situations in which students' decisions strongly depend on these costs. However, to highlight the role of mobility costs necessarily sets aside the role played by the prestige of attending the home campus of a top university. Indeed, there is substantial evidence suggesting that many students prefer to attend a top university even if the same institution opened a branch campus (for example, consider the proportion of Asian students in top American universities). In our framework, this corresponds to setting $t<0$ when attending university $A$. In words, the gain (in terms of reputation, extra salary independent of ability, and the like) for attending the home campus of a top university more than offsets the mobility costs for doing so. This section is devoted to explore this case.

Let us re-label University $A$ as "top university". As in the previous analysis, University $A$ sets higher admission standards than University $B$. Moreover, denote $t_{A}<0$ as the difference between mobility costs and the benefit of attending a top university. Nothing changes for University $B$, so that a student from the developing country who attends the home campus of University $B$ still bears a cost of $t>0$. Lemma 2 changes as follows.

Lemma 4: Let Assumption 1 hold, and $t_{A}<0$. Then the number of students being admitted to each university is:

$$
\begin{aligned}
& n_{A}= \begin{cases}(1+\beta)\left(1-x_{A 1}\right) & \text { no BC } \\
\left(1-x_{A 1}\right)(1+\beta)+\left(1-x_{A 2}\right)(1-\beta) & A B C \\
(1+\beta)\left(1-x_{A 1}\right) & B B C \\
\left(1-x_{A 1}\right)(1+\beta)+\left(1-x_{A 2}\right)(1-\beta) & B, A, B C\end{cases} \\
& n_{B}= \begin{cases}(1+\beta)\left(x_{A 1}-x_{B 1}\right) & \text { no BC } \\
(1+\beta)\left(x_{A 1}-x_{B 1}\right) & A B C \\
\left(x_{A 1}-x_{B 1}\right)+\left(x_{A 1}-x_{B 1}\right)+\left(1-x_{A 1}\right)(1-\beta) & B B C \\
\left(x_{A 1}-x_{B 1}\right)+\left(x_{A 1}-x_{B 1}\right) & B, A, B C\end{cases}
\end{aligned}
$$

We solve the game following the previous structure. Equations [13], [20], [22] and [21] in Appendix A.2 are the equilibrium payoffs according to the decisions of opening a $\mathrm{BC}$ in the first stage. Using these results, we examine the investment decisions in $B C$ in the first stage. We start by examining the strategy of 
university $A$ according to university $B$ decisions. If university $B$ plays $B C$, university $A$ would do the same for $\pi_{A 1}^{F F}>\pi_{A 1}^{N F}$, whereas if university $B$ plays $N$, university $A$ would play $B C$ for $\pi_{A 1}^{F N}>\pi_{A 1}^{N N}$. Both inequalities hold for all:

$$
F<F_{A}^{T o p} \equiv \frac{(1-\beta)(f+w)^{2}}{4(c+w)-4 \beta c} .
$$

Consider next the strategy of university $B$. If university $A$ plays $B C$, university $B$ would do the same for $\pi_{B 1}^{F F}>\pi_{B 1}^{F N}$, which occurs for all:

$$
\begin{aligned}
& F<\widehat{F}_{B}^{T o p} \equiv \frac{(f+w)^{2}}{16(c+w)(c+w-\beta c)^{2}(\beta c+c+w)^{3}} \times \\
& {\left[4(\beta-1)^{2}(\beta+1)^{3} c^{5}+4\left(-\beta^{5}+2 \beta^{4}-6 \beta^{2}+\beta+4\right) c^{4} w+(\beta+1)((\beta-2) \beta(4 \beta+17)+25) c^{3} w^{2}\right.} \\
& \left.(\beta(\beta(3 \beta-11)-15)+19) c^{2} w^{3}+(7-\beta(2 \beta+7)) c w^{4}-(\beta-1) w^{5}\right] .
\end{aligned}
$$

If university $A$ plays $N$, university $B$ would play $B C$ the same for $\pi_{B 1}^{N F}>\pi_{B 1}^{N N}$, which takes place for:

$$
\begin{aligned}
& F<\bar{F}_{B}^{T o p} \equiv \\
& \frac{(f+w)^{2}\left(4(\beta+1)^{3} c^{3}-4(\beta+1)^{2}(2 \beta-3) c^{2} w+\left((\beta-11) \beta^{2}+12\right) c w^{2}+(\beta-4)(\beta-1) w^{3}\right)}{16(c+w)(\beta c+c+w)^{3}}
\end{aligned}
$$

For the sake of tractability, we set $w=c$. The results depend on the proportion of privileged students, as summarised in the following lemma.

Lemma 5: Let Assumption 1 hold, $t_{A}<0$ and denote $\widehat{\beta} \cong 0.454$ and $\bar{\beta} \cong 0.985$. For [1] $\quad \beta<\widehat{\beta}$, the chain of inequalities is $F_{A}^{T o p}>\bar{F}_{B}^{T o p}>\widehat{F}_{B}^{T o p}$;

[2] $\widehat{\beta}<\beta<\bar{\beta}$, the chain of inequalities is $\bar{F}_{B}^{T o p}>F_{A}^{T o p}>\widehat{F}_{B}^{\text {Top }}$;

[3] $\beta>\bar{\beta}$, the chain of inequalities is $\bar{F}_{B}^{T o p}>\widehat{F}_{B}^{\text {Top }}>F_{A}^{\text {Top }}$.

Case [1] of Lemma 1 is qualitatively similar to the baseline model. When the proportion of privileged students is low, the top university has the same strategic behaviour of the elitist university. This is intuitive. Since a low proportion of students can afford to move to the developed country in order to attend the top university, the top university has an incentive in opening a BC.

The result changes for Cases [2] and [3] as follows. 
Proposition 4: Let Assumption 1 hold, $t_{A}<0$ and $\widehat{\beta}<\beta$. For all:

1. $F>\bar{F}_{B}^{T o p}$, neither university opens a $B C$, the equilibrium is $[N ; N]$;

2. $\bar{F}_{B}^{T o p}>F>F_{A}^{T o p}$, university $B$ opens a $B C$ and university $A$ does not, the equilibrium is $[N ; B C]$;

3. $F<F_{A}^{T o p}$, both universities open a $B C$, the equilibrium is $[B C ; B C]$.

Proposition 4 identifies a case ([2]) where it is the non-elitist University $B$ that opens a BC while the top university does not. This is in contrast to the baseline case of Proposition 3. This result is due to the large proportion of privileged students, who can afford to move to the developed country. In this case University $A$ has little incentive in opening a BC.

\section{Concluding Remarks}

We have analysed competition among universities and its effect in opening a branch campus. Competition among universities from a developed country takes place by both setting admission standards and deciding whether or not to open a branch campus in a developing country. Students living in the developing country can attend university only if a branch campus is opened or if they can afford to move to the developed country. An increase in the graduate wage increases the incentives for opening a branch campus, although the incentive is stronger for the elitist than the non-elitist university. Three possible equilibria emerge: (i) no branch campus, when the investment costs are too high, (ii) a branch campus is opened by the elitist university only and (iii) two branch campuses. An increase in the proportion of privileged students increases the chance of an equilibrium of type (ii) to the detriment of equilibrium (i). By contrast, in the case of a "Top" university the branch campus is opened only by the non-elitist university; this latter result is driven by the proportion of "privileged" students.

The paper could be further enriched by considering different tuition fees between universities in the developing and developed country. Tuition fees are usually lower in the branch rather than the main campus. However, this extension would have complicated the analysis by not adding so much. Indeed, the difference in tuition fees can be captured by the mobility costs, so in effect is already captured by the analysis.

Acknowledgements: We are grateful to Gianni De Fraja, Elena Del Rey, Simona Fabrizi, Francisco Martinez-Mora, Lynne Pepall, Pierre Picard, Sergey Popov, Dan Richards, the Editor Burkhard C. Schipper, two anonymous referees and seminar audiences at AMES 2014 (Taipei), EARIE 2014 (Milan), CNR 2015 (Rome) and PET 2015 (Luxembrourg) for helpful comments. 


\section{Appendix}

\section{A.1 Proof of Lemma 1}

Begin by noting that, given the additive and separable nature of a university's objective function (see expressions [7] and [8]), each admission standard is determined for each country separately, depending exclusively on the competitor's response within that country. This allows us to focus on setting the admission standard in a single country.

Prior to doing this, we consider a useful benchmark case where there is only one university operating in country 1 , say $A$. This monopolistic university could either operate a branch campus or not. In the absence of a BC, it sets standard $x$ and for $T=0$ will admit $n_{A 1}=2(1-G(x))$ students while for $T=t$ it will admit $n_{A 1}=(1+\beta)(1-G(x))$. The associated first-order conditions are:

$$
\begin{gathered}
2\left(W_{n}(\cdot)+f W_{R}(\cdot)-W_{R} c^{\prime}(\cdot)\right) g(x)=W_{\Theta}(\cdot) \theta_{x}(\cdot) \\
(1+\beta)\left(W_{n}(\cdot)+f W_{R}(\cdot)-W_{R} c^{\prime}(\cdot)\right) g(x)=W_{\Theta}(\cdot) \theta_{x}(\cdot) .
\end{gathered}
$$

Denote the solutions to [7] and [8] as $x_{m}$ and $x_{m T}$ respectively. ${ }^{11}$ With a BC, only the case $T=t$ is relevant, the standards are $x_{1}$ and $x_{2}$, one for each campus location and the students admitted are $n_{A 1}+n_{A 2}=\left(1-G\left(x_{1}\right)\right)+\left(1-G\left(x_{2}\right)\right)$. The solutions to the relevant first-order conditions (not shown) yield standards $x_{M 1}=x_{M 2}$.

We now return to the question of symmetric standards and consider the case (1) in the main text (where no university opens a BC), in more detail. Suppose $A$ and $B$ choose symmetric standards, $x_{A}=x_{B}=x_{m}$, in equilibrium and split evenly students' demand; ${ }^{12}$ any value of common admission standard different from $x_{m}$ necessarily violates the first-order condition (1) as $A$ and $B$ share the market and effectively act as a local monopoly. ${ }^{13}$ We now show that one university, say $B$, has an incentive to deviate from the symmetric equilibrium. Suppose $B$ sets $x_{B}=x_{m}-\varepsilon$, with $\varepsilon>0$ small. This deviation leads to a change in $B$ 's payoff approximated by:

11 Given the properties of $W$ these solutions are unique maxima.

12 This assumption is innocuous for the fact that, as we are about to prove, the symmetric configuration is not an equilibrium. Given the university incentives to raise its admission standard compared to the competitor, whatever initial demand in the symmetric configuration will be modified accordingly.

13 The case for $t=T$ is similar and thus ommitted. 


$$
-\varepsilon \times\left(\left.\left(W_{n}(\cdot)+f W_{R}(\cdot)-W_{R}(\cdot) c^{\prime}(\cdot)\right) \frac{\partial n_{B}\left(x_{m}, x_{m}\right)}{\partial x_{B}}\right|_{x_{B}<x_{m}}+W_{\Theta}(\cdot) \theta_{x}(\cdot)\right)
$$

where

$$
\left.\frac{\partial n_{B}\left(x_{m}, x_{m}\right)}{\partial x_{B}}\right|_{x_{B}<x_{m}}=\lim _{h \rightarrow 0^{-}} \frac{n_{B}\left(x_{m}, x_{m}+h\right)-n_{B}\left(x_{m}, x_{m}\right)}{h}
$$

is the left partial derivative of $n_{B}\left(x_{m}, x_{m}\right)$. For $x_{B}<x_{m}, n_{B}\left(x_{m}, x_{B}\right)=$ $2\left(G\left(x_{m}\right)-G\left(x_{B}\right)\right)$, so that

$$
\left.\frac{\partial n_{B}\left(x_{m}, x_{m}\right)}{\partial x_{B}}\right|_{x_{B}<x_{m}}=\lim _{h \rightarrow 0^{-}} \frac{2\left(G\left(x_{m}\right)-G\left(x_{m}+h\right)\right)}{h}=-2 g\left(x_{m}\right)
$$

and [9] becomes

$$
-\varepsilon \times\left(-2\left(W_{n}(\cdot)+f W_{R}(\cdot)-W_{R}(\cdot) c^{\prime}(\cdot) g\left(x_{m}\right)+W_{\Theta}(\cdot) \theta_{x}(\cdot)\right)\right.
$$

and using [7]:

$$
\varepsilon W_{\Theta}(\cdot) \theta_{x}(\cdot)>0 \text {. }
$$

A small reduction in the standard increases $B$ 's payoff, hence symmetric standards cannot be an equilibrium. This type of argument can also apply to the remaining cases (2), (3) and (4), noting that in the case where only one university opens a $\mathrm{BC}$ in country 2 it behaves as a local monopoly in the setting of the standard, while it still competes in country 1.

Finally, notice that there is an alternative possibility with $B$ raising its standard by $\varepsilon$ or more. If both universities keep raising their standards, they eventually reach a configuration where $x_{A}=x_{B}=1$, and no student is admitted. This outcome maximises the average quality of students, but minimises the total number of admitted students. Hence there is an incentive to deviate by lowering the standard to raise the number of admissions.

\section{A.2 Proof of Proposition 1}

The proposition follows directly from $S^{\prime}\left(x_{i j}\right)>0$ and the discussion in the preceding section. The following lemma gives university attendance according to a student's ability.

Lemma 6 Consider students living in Country 1. University $i \in\{A, B\}$ sets standard $x_{i 1}$, and $x_{A 1}>x_{B 1}$. 
1. Let student with ability $\theta_{A 1}$ attend university $A$. Then all students with ability $\theta>\theta_{A 1}$ also attend university $A$.

2. Let student with ability $\theta_{B 1}$ attend university $B$. Then all students with ability $\theta_{B 1}<\theta<\theta_{A 1}$ also attend university $B$.

This follows from the fact that a student with higher ability gains more from attendance at a university with a stricter admission test (Epple and Romano 1998; De Fraja and Iossa 2002). Proposition 1 is an immediate consequence of Lemma 6 and the characterization of a student's ability.

\section{A.3 Proof of Proposition 2}

The following lemma is the equivalent of Lemma 6 for students of Country 2.

Lemma 7 Consider students living in Country 2. Let university $i \in\{A, B\}$ set standard $x_{i j}$ for their site in Country $j$ with $x_{A j}>x_{B j}$ (assumption 1).

1. No BC:

a. Let a privileged student with ability $\theta_{A 1}$ attend university $A$. Then $\beta$ students with ability $\theta>\theta_{A 1}$ also attend university $A$.

b. Let a privileged student with ability $\theta_{B 1}$ attend university $B$. Then $\beta$ students with ability $\theta_{B 1}<\theta<\theta_{A 1}$ also attend university $B$.

2. University $A$ operates BC:

a. Let a student with ability $\theta_{A 2}$ attend university $A$. Then all students with ability $\theta>\theta_{A 2}$ also attend university $A$.

b. Let a privileged student with ability $\theta_{B 1}$ attend university $B$. Then $\beta$ students with ability $\theta_{B 1}<\theta<\theta_{A 1}$ also attend university $B$.

3. Universities $A$ and $B$ operate $\mathrm{BC}$ :

a. Let a student with ability $\theta_{A 2}$ attend university $A$. Then all students with ability $\theta>\theta_{A 2}$ also attend university $A$.

b. Let a student with ability $\theta_{B 2}$ attend university $B$. Then all students with ability $\theta_{B 2}<\theta<\theta_{A 2}$ also attend university $B$.

4. University $B$ operates $\mathrm{BC}$, and $t \leq t^{*}$ :

a. Let a privileged student with ability $\theta_{A 1}$ attend university $A$. Then $\beta$ students with ability $\theta>\theta_{A 1}$ also attend university $A$.

b. Let a student with ability $\theta_{B 2}$ attend university $B$. Then all students with ability $\theta_{B 2}<\theta<\theta_{A 1}$ and $1-\beta$ students with ability $\theta>\theta_{A 1}$ also attend university $B$. 


\section{University $B$ operates $\mathbf{B C}$, and $t>t^{\star}$ :}

a. No students from Country 2 attend university $A$.

b. Let a student with ability $\theta_{B 2}$ attend university $B$. Then all students with ability $\theta>\theta_{B 2}$ also attend university $B$.

Notice that, in the case in which university $B$ is the only university to open a BC and $t \leq t^{\star}$ (part 4 in proposition 2 above), students with ability at least $\theta_{A 1}$ attend university $A$ only if they are privileged. If they are not, they will attend the $\mathrm{BC}$ of university $B$. Conversely, in the case in which university $B$ operates a $\mathrm{BC}$ only and $t>t^{\star}$, then none of the students of ability at least $\theta_{A 1}$ from Country 2 will attend university $A$, since the increase in utility from attending university $A$ is more than offset by the mobility costs.

\section{A.4 Proof of Lemma 3}

Proof. A student in Country 2 with ability equal or greater than $\theta_{A}$ is indifferent between moving to Country 1 to attend university $A$ and attending the $\mathrm{BC}$ of university $B$ if

$$
w x_{A 1}^{N F}\left(t \leq t^{\star}\right)-t^{\star}=w x_{B 2}^{N F}\left(t>t^{\star}\right),
$$

which occurs for

$$
t^{\star}=\frac{w c \beta(w+f)}{2(w+c)[w+c(1+\beta)]} .
$$

Finally, it is necessary to verify that indeed below $t^{\star}$ the condition

$$
w x_{A 1}^{N F}\left(t \leq t^{\star}\right)-t>w x_{B 2}^{N F}\left(t \leq t^{\star}\right)
$$

holds and, accordingly, above $t^{\star}$ the condition

$$
w x_{A 1}^{N F}\left(t>t^{\star}\right)-t<w x_{B 2}^{N F}\left(t>t^{\star}\right)
$$

holds. Inequality [10] holds for all

$$
t<\widetilde{t} \equiv \frac{w \beta(w+f)(w+4 c)}{4(w+c)[w+c(1+\beta)]},
$$

whereas inequality [11] holds for all

$$
t>\widehat{t} \equiv 0 .
$$


Finally, notice that $\widehat{t}<t^{\star}<\widetilde{t}$, thus the threshold $t^{\star}$ satisfies the conditions [10] and [11] along the entire parameter range.

\section{A.5 Calculations for Section 2.5 - Admission Standards and Payoffs}

No BC: in the case where neither university $A$ nor $B$ open a $\mathrm{BC}$, the first order conditions with respect to $x_{A}, x_{B}$ are:

$$
\begin{aligned}
& \frac{\partial \pi_{A}}{\partial x_{A 1}}=(1+\beta)\left[w\left(1-2 x_{A 1}\right)+2(1+\beta) c\left(1-x_{A 1}\right)\right]=0, \\
& \frac{\partial \pi_{B}}{\partial x_{B 1}}=(1+\beta)\left[w\left(x_{A 1}-2 x_{B 1}\right)+2(1+\beta) c\left(x_{A 1}-x_{B 1}\right)\right]=0 .
\end{aligned}
$$

Solving yields the admission thresholds in equilibrium:

$$
x_{A 1}^{N N}=\frac{w+2 c(1+\beta)-f}{2[w+c(1+\beta)]}, x_{B 1}^{N N}=\frac{w(w-3 f)+4 c^{2}(1+\beta)^{2}+4 c(w-f)(1+\beta)}{4[w+c(1+\beta)]^{2}},
$$

and the universities payoffs are:

$$
\begin{aligned}
& \pi_{A}^{N N}=\frac{(w+f)^{2}(61+\beta)}{4[w+c(1+\beta)]} \\
& \pi_{B}^{N N}=\frac{(w+f)^{2}[w+2 c(1+\beta)]^{2}(1+\beta)}{16[w+c(1+\beta)]^{3}} .
\end{aligned}
$$

Notice that

$$
x_{A 1}^{N N}-x_{B 1}^{N N}=\frac{(w+f)[w-f+2 c(1+\beta)]}{4[w+c(1+\beta)]^{2}}>0 .
$$

University $A$ BC: if university $A$ opens a $\mathrm{BC}$ but not university $B$, the first order conditions with respect to $x_{A}, x_{B}$ yield:

$$
\begin{aligned}
& \frac{\partial \pi_{A}}{\partial x_{A 1}}=(w+2 c)\left(1-x_{A 1}\right)-w x_{A 1}-f=0, \\
& \frac{\partial \pi_{A}}{\partial x_{A 2}}=(w+2 c)\left(1-x_{A 2}\right)-w x_{A 2}-f=0, \\
& \frac{\partial \pi_{B}}{\partial x_{B 1}}=(1+\beta)\left[(w+2 c(1+\beta))\left(x_{A 1}-x_{B 1}\right)-w x_{B 1}-f\right]=0 .
\end{aligned}
$$


The admission threshold in equilibrium is then:

$$
\begin{aligned}
& x_{A 1}^{F N}=x_{A 2}^{F N}=\frac{w+2 c-f}{2(w+c)}, \\
& x_{B 1}^{F N}=\frac{w(w-3 f)+4 c^{2}(1+\beta)+2 c(w-f)(2+\beta)}{4[w+c(1+\beta)]^{2}} .
\end{aligned}
$$

Thus the universities profits are:

$$
\begin{aligned}
\pi_{A}^{F N} & =\frac{(w+f)^{2}}{2(w+c)}-F \\
\pi_{B}^{F N} & =\frac{(w+f)^{2}(w+2 c)^{2}(1+\beta)}{16(w+c)^{2}[w+c(1+\beta)]}
\end{aligned}
$$

Notice that

$$
x_{A 1}^{F N}-x_{B 1}^{F N}=\frac{(w+f)(w+2 c)}{4(w+c)[w+c(1+\beta)]}>0 .
$$

University $A$ and $B$ BC: if both universities open a BC, the first order conditions with respect to $x_{A}, x_{B}$ are:

$$
\begin{aligned}
& \frac{\partial \pi_{A}}{\partial x_{A 1}}=(w+2 c)\left(1-x_{A 1}\right)-w x_{A 1}-f=0, \\
& \frac{\partial \pi_{A}}{\partial x_{A 2}}=(w+2 c)\left(1-x_{A 2}\right)-w x_{A 2}-f=0, \\
& \frac{\partial \pi_{B}}{\partial x_{B 1}}=(w+2 c)\left(x_{A 1}-x_{B 1}\right)-w x_{B 1}-f=0 . \\
& \frac{\partial \pi_{B}}{\partial x_{B 2}}=(w+2 c)\left(x_{A 2}-x_{B 2}\right)-w x_{B 2}-f=0 .
\end{aligned}
$$

The admission threshold in equilibrium is:

$$
\begin{aligned}
& x_{A 1}^{F F}=x_{A 2}^{F F}=\frac{w+2 c-f}{2(w+2 c)}, \\
& x_{B 1}^{F F}=x_{B 2}^{F F}=\frac{(w+2 c)^{2}-f(3 w+4 c)}{4(w+c)^{2}},
\end{aligned}
$$

where the superscript indicates that both universities invest in $B C$. Therefore the universities payoffs are:

$$
\begin{aligned}
& \pi_{A}^{F F}=\frac{(w+f)^{2}}{2(w+c)}-F \\
& \pi_{B}^{F F}=\frac{(w+2 c)^{2}(w+f)^{2}}{8(w+2 c)^{3}}-F .
\end{aligned}
$$


Notice that

$$
x_{A 1}^{F F}-x_{B 1}^{F F}=\frac{(w+f)(w+2 c)}{4(w+c)^{2}}>0 .
$$

University $B$ BC: as previously stated, in the case in which university $B$ is the only one who opens a BC, then there are two possibilities according to whether $t \xi t^{\star}$. First we consider the case when $t \leq t^{\star}$, so that $w x_{A}-t \geq w x_{B}$ (see Definition 1). According to Lemma 2 demands for university $A$ and $B$ are:

$$
\begin{aligned}
& n_{A}=(1+\beta)\left(1-x_{A 1}\right), \\
& n_{B}=\left(x_{A 1}-x_{B 1}\right)+\left(1-x_{A 1}\right)(1-\beta)+\left(x_{A 1}-x_{B 2}\right) .
\end{aligned}
$$

The first order conditions with respect to $x_{A 1}, x_{B 1}$ and $x_{B 2}$ are:

$$
\begin{aligned}
& \frac{\partial \pi_{A}}{\partial x_{A 1}}=(1+\beta)\left[(w+2 c(1+\beta))\left(1-x_{A 1}\right)-w x_{A 1}-f\right]=0, \\
& \frac{\partial \pi_{B}}{\partial x_{B 1}}=(w+2 c)\left(x_{A 1}-x_{B 1}\right)-w x_{B 1}-f=0, \\
& \frac{\partial \pi_{B}}{\partial x_{B 2}}=(w-2 c)\left[1-\beta\left(1-x_{A 1}\right)-x_{B 2}\right]-w x_{B 2}-f=0 .
\end{aligned}
$$

The admission thresholds in equilibrium are:

$$
\begin{aligned}
& x_{A 1}^{N F}\left(t \leq t^{\star}\right)=\frac{w+2 c(1+\beta)-f}{2[w+c(1+\beta)]}, \\
& x_{B 1}^{N F}\left(t \leq t^{\star}\right)=\frac{w(w-3 f)+4 c^{2}(1+\beta)+2 c(w-f)(2+\beta)}{4(w+c)[w+c(1+\beta)]}, \\
& x_{B 2}^{N F}\left(t \leq t^{\star}\right)=\frac{4 c^{2}(1+\beta)-w[f(2+\beta)-w(2-\beta)]+2 c[3 w-f(1+2 \beta)]}{4(w+c)[w+c(1+\beta)]}
\end{aligned}
$$

where the superscript indicates that university $A$ did not invest in $\mathrm{BC}(N)$ and university $B$ did $(F)$. Therefore the universities payoffs are:

$$
\begin{aligned}
& \pi_{A 1}^{N F}\left(t \leq t^{\star}\right)=\frac{(w+f)^{2}(1+\beta)}{4[w+c(1+\beta)]}, \\
& \pi_{B 1}^{N F}\left(t \leq t^{\star}\right)=\frac{(w+f)^{2}\left[8 c^{2}(1+\beta)^{2}+4 w c(3-\beta)(1+\beta)+w^{2}(5-\beta(4-\beta))\right]}{16(w+c)[w+c(1+\beta)]}-F .
\end{aligned}
$$

We then consider the case when $w x_{A 1}-t<w x_{B 2}$ (i. e., $t>t^{\star}$ ). In this case, the demands for university $A$ and $B$ are:

$$
\begin{aligned}
& n_{A}=\left(1-x_{A 1}\right), \\
& n_{B}=\left(x_{A 1}-x_{B 1}\right)+1-x_{B 1} .
\end{aligned}
$$


The first order conditions are:

$$
\begin{aligned}
& \frac{\partial \pi_{A}}{\partial x_{A 1}}=(w+2 c)\left(1-x_{A 1}\right)-w x_{A 1}-f=0, \\
& \frac{\partial \pi_{B}}{\partial x_{B 1}}=(w+2 c)\left(x_{A 1}-x_{B 1}\right)-w x_{B 1}-f=0, \\
& \frac{\partial \pi_{B}}{\partial x_{B 2}}=(w+2 c)\left(1-x_{B 2}\right)-w x_{B 2}-f=0 .
\end{aligned}
$$

The admission thresholds in equilibrium are:

$$
\begin{aligned}
& x_{A 1}^{N F}\left(t>t^{\star}\right)=\frac{w+2 c-f}{2(w+c)}, \\
& x_{B 1}^{N F}\left(t>t^{\star}\right)=\frac{(w+2 c)-f(3 w+4 c)}{8\left(w^{2}+3 w c+2 c^{2}\right)}, \\
& x_{B 2}^{N F}\left(t>t^{\star}\right)=\frac{w+2 c-f}{2(w+c)},
\end{aligned}
$$

and universities payoffs are:

$$
\begin{aligned}
& \pi_{A 2}^{N F}\left(t>t^{\star}\right)=\frac{(w+f)}{4(w+c)} \\
& \pi_{B 2}^{N F}\left(t>t^{\star}\right)=\frac{(w+f)^{2}\left(5 w^{2}+12 w c+8 c^{2}\right)}{16(w+c)^{3}}-F
\end{aligned}
$$

\section{A.6 Calculations for Section 2.6 - "Top" University, Admission Standards and Payoffs}

For brevity, we omit the derivation of the first order conditions. The case No BC is identical to the baseline case in Section 2.5, see expressions [12] and [13].

University $A$ BC: if university $A$ opens a $B C$ but not university $B$, the admission threshold in equilibrium is:

$$
\begin{aligned}
& x_{A 1}^{F N}=\frac{w+2(\beta+1) c-f}{2[w+c(1+\beta)]} \\
& x_{A 2}^{F N}=\frac{w+2(1-\beta) c-f}{2[w+c(1-\beta)]}, \\
& x_{B 1}^{F N}=\frac{4(1+\beta)^{2} c^{2}+4(\beta+1) c(w-f)+w(w-3 f)}{4[w+c(1+\beta)]^{2}} .
\end{aligned}
$$


Notice that

$$
x_{A 1}^{F N}-\chi_{B 1}^{F N}=\frac{(f+w)(2(\beta+1) c+w)}{4(\beta c+c+w)^{2}}>0,
$$

and

$$
x_{A 1}^{F N}-x_{A 2}^{F N}=\frac{c \beta(w+f)}{[w+c(1+\beta)][w+c(1-\beta)]}>0 .
$$

Unlike the baseline case, the admission requirements for the top university in the developed country are higher than in the developing country. The universities payoffs are:

$$
\begin{aligned}
& \pi_{A}^{F N}=\frac{[(w+2) w+1](c+w)-\beta^{2} c(1+w)^{2}}{2\left[(c+w)^{2}-\beta^{2} c^{2}\right]}-F, \\
& \pi_{B}^{F N}=\frac{(\beta+1)(f+w)^{2}[2(\beta+1) c+w]^{2}}{16[w+c(1+\beta)]^{3}} .
\end{aligned}
$$

University $A$ and $B$ BC: if both universities open a BC, the admission thresholds in equilibrium are:

$$
\begin{aligned}
& x_{A 1}^{F F}=\frac{w+2(1+\beta) c-f}{2[w+c(1+\beta)]}, \\
& x_{A 2}^{F F}=\frac{w+2(1-\beta) c-f}{2[w+c(1-\beta)]}, \\
& x_{B 1}^{F F}=\frac{2(2+\beta) c(w-f)+4(1+\beta) c^{2}+w(w-3 f)}{4(c+w)[w+c(1+\beta)]}, \\
& x_{B 2}^{F F}=\frac{2(2-\beta) c(w-f)+4(1-\beta) c^{2}+w(w-3 f)}{4(c+w)[w+c(1-\beta)]} .
\end{aligned}
$$

Notice that

$$
\begin{aligned}
& x_{A 1}^{F F}-x_{B 1}^{F F}=\frac{(w+1)[w+2(1+\beta) c]}{4(c+w)[w+c(1+\beta)]}>0, \\
& x_{A 2}^{F F}-x_{B 2}^{F F}=\frac{(w+1)[w+2(1-\beta) c]}{4(c+w)[w+c(1-\beta)]}>0 .
\end{aligned}
$$

The universities payoffs are:

$$
\begin{aligned}
& \pi_{A}^{F F}=\frac{(f+w)^{2}\left(w+c-\beta^{2} c\right)}{2(c+w)^{2}-2 \beta^{2} c^{2}}-F \\
& \pi_{B}^{F F}=\frac{(f+w)^{2}\left[(c+w)^{2}(2 c+w)^{2}+4 \beta^{4} c^{4}-\beta^{2} c^{2}\left(8 c^{2}+12 c w+3 w^{2}\right)\right]}{8(c+w)\left[(c+w)^{2}-\beta^{2} c^{2}\right]^{2}}-F .
\end{aligned}
$$


University $B$ BC: The admission threshold in equilibrium is:

$$
\begin{aligned}
& x_{A 1}^{N F}=\frac{w+2(1+\beta) c-f}{2[w+c(1+\beta)]}, \\
& x_{B 1}^{N F}=\frac{2(\beta+2) c(w-f)+4 c^{2}(1+\beta)+w(w-3 f)}{4(c+w)[w+c(1+\beta)]}, \\
& x_{B 2}^{N F}=\frac{w[(2-\beta) w-(\beta+2) f]+4 c^{2}(1+\beta)+2 c(3 w-2 \beta f-f)}{4(c+w)[w+c(1+\beta)]} .
\end{aligned}
$$

Notice that

$$
x_{A 1}^{N F}-x_{B 1}^{N F}=\frac{(w+f)[w+2(\beta+1) c]}{4(w+c)[w+c(1+\beta)]}>0
$$

and

$$
x_{B 1}^{N F}-\chi_{B 2}^{N F}=\frac{(1-\beta)(w+2 c)(w+f)}{4(w+c)[w+c(1+\beta)]}>0,
$$

saying that University $B$ sets higher admission standard in the home campus. Finally, the universities payoffs are:

$$
\begin{aligned}
& \pi_{A 1}^{N F}=\frac{(1+\beta)(f+w)^{2}}{4[w+c(1+\beta)]}, \\
& \pi_{B 1}^{N F}=\frac{(f+w)^{2}\left[8(1+\beta)^{2} c^{2}+4(3-\beta)(1+\beta) c w+(5-(4-\beta) \beta) w^{2}\right]}{16(c+w)[w+c(1+\beta)]^{2}}-F
\end{aligned}
$$

\section{References}

Becker, R. 2009. “International Branch Campuses: Markets and Strategies”. Report of the Observatory on Borderless Higher Education.

Carroni, E., B. Cesi, and D. Paolini. 2015. "Peer Group, Distance and Tuition Fees: When Widening University Participation is Still Better." CRENOS working paper 06.

Cesi, B., and D. Paolini. 2014. Peer Group and Distance: When Widening University Participation Is Better. University of Manchester: The Manchester School, 82:110-32.

De Fraja, G., and E. Iossa. 2002. "Competition among Universities and the Emergence of the Elite Institution." Bulletin of Economic Research 54:275-93.

Del Rey, E. 2001. "Teaching Versus Research: A Model of State University Competition." Journal of Urban Economics 49:356-73. 
Epple, D., and R. E. Romano. 1998. "Competition between Private and Public Schools, Vouchers and Peer-Group Effects." American Economic Review 88:33-62.

Lien, D. 2006. "Borderless Education and Domestic Program." Education Economics 14:297-308.

Lien, D. 2008. "Economic Analysis of Transnational Education." Education Economics 16:149-66.

Lien, D., and Y. Wang. 2010. "The Effects of a Branch Campus." Education Economics 20:1-16.

Pepall, L., and D. Richard. 2014. "Competition, Selectivity and Innovation in the Higher Educational Market," Discussion Papers Series, Department of Economics, Tufts University 0782, Department of Economics, Tufts University.

Ziguras, C. 2003. The Impact of the GATS on Transnational Tertiary Education: Comparing Experiences of New Zealand, Australia, Singapore and Malaysia. Australian Education Researcher 30:89-109. 